\title{
BLOOD SUGAR LEVELS IN BABIES BORN OF DIABETIC MOTHERS
}

\author{
BY \\ GEORGE M. KOMROWER \\ From St. Mary's Hospitals, Manchester, and the Department of Child Health of the University of Manchester
}

(RECEIVED FOR PUBLICATION SEPTEMBER 3, 1953)

Many observers have reported upon the blood sugar levels determined during the first days of life of normal infants; and it is generally agreed that there is considerable variation in the figures of different babies, and also some instability of the levels in each individual infant under investigation, the figures being invariably lower than those in older persons (Creery and Parkinson, 1953; Greenwald and Pennell, 1930; Hartmann and Jaudon, 1937; Ketteringham and Austin, 1938; McKittrick, 1940; Norval, Kennedy and Berkson, 1949; Smith, 1951; Wachter, 1949).

There is less information concerning the blood sugar levels of the infants born of diabetic mothers, but the evidence suggests an early and rapid fall to a low level followed by a slow rise to more normal levels (Haslewood and Strookman, 1939; Joslin, Root, White and Marble, 1952; Miller and Ross, 1940; Oakley, 1953; Pedersen, 1952; Peel and Oakley, 1950; Reis, DeCosta and Allweiss, 1950).

It has been possible to make some observations on 21 normal infants and 40 infants born of diabetic mothers, and figures are produced for comparison. Twenty-five of the 40 'diabetic' babies were given $50 \%$ glucose at set intervals during the first eight hours of life, a total of $2 \mathrm{~g}$. of glucose being given in all, but no further feeding was attempted until the infants demanded. This regime, based on the work of Reis and his colleagues in Chicago (1950), was employed as part of an M.R.C. investigation into pregnancy in diabetes: the remainder were not given glucose and feeding was only begun when the infants cried hungrily.

The majority of the 'diabetic' babies were delivered by Caesarean section in the thirty-seventh to thirtyeighth week, the mothers being given $30 \mathrm{~g}$. glucose within two hours of the operation.

Blood sugar estimations were made on the cord blood (umbilical vein), and on heel blood obtained at half hour, one hour, two hours, four hours, 12 hours and 24 hours. The method of estimation was a modification of the method employed by Haslewood and Strookman (1939), namely, $0.1 \mathrm{ml}$. of whole blood is pipetted into $3.70 \mathrm{ml}$. of isotonic sodium sulphate-copper sulphate solution in a conical centrifuge tube; $\mathbf{0} \cdot \mathbf{2} \mathrm{ml}$. of sodium tungstate is added, and the mixture is well shaken. The precipitated proteins and copper tungstate are spun down in the centrifuge; $0.5 \mathrm{ml}$. of the supernatant fluid ( $\equiv 0.0125 \mathrm{ml}$. blood) is mixed with $1 \mathrm{ml}$. of the mixed copper reagent in a $\frac{3}{4}$ in. diameter test-tube. The tube, stoppered with cotton wool, is placed in a boiling water-bath for exactly 10 minutes. After immediate cooling, $3 \mathrm{ml}$. of the phosphomolybdic acid reagent are added. The colour is compared with that produced by $1 \mathrm{ml}$. of a standard glucose solution in benzoic acid, treated in the same way as the blood filtrate. Duplicate readings were made as often as possible but as it was not feasible to obtain the full amount of blood on all occasions several of the results have been discarded.

The normal infants were born in the thirty-ninth or fortieth week by ordinary forces and suffered no complications in the neonatal period. They were not fed for 12 hours, when they were offered glucose saline; if this was taken satisfactorily the child

TABLE 1

NORMAL CONTROLS

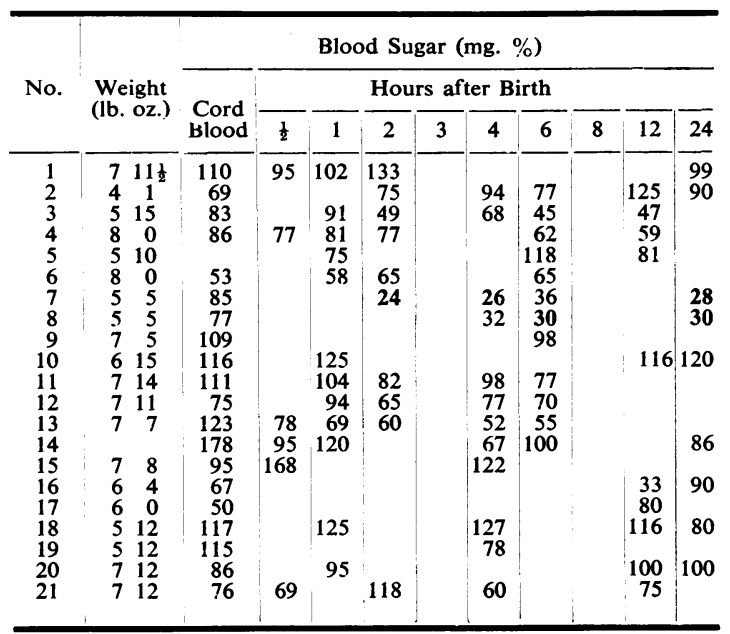


was put to the breast at 15 hours and routine feeding begun (Table 1). These babies showed a wide scatter of blood sugar levels at any one interval of time (Fig. 1), but the bulk of the results lay around the mean (Fig. 1). The graph does not show any sudden infant usually stabilized slowly at a rather lower level than that of the normal infant (Figs. 2 and 3).

A comparison has been made between the infants given glucose ( 25 in all) during the first eight hours $(D+g)$ and those (15 in all) who were left un-

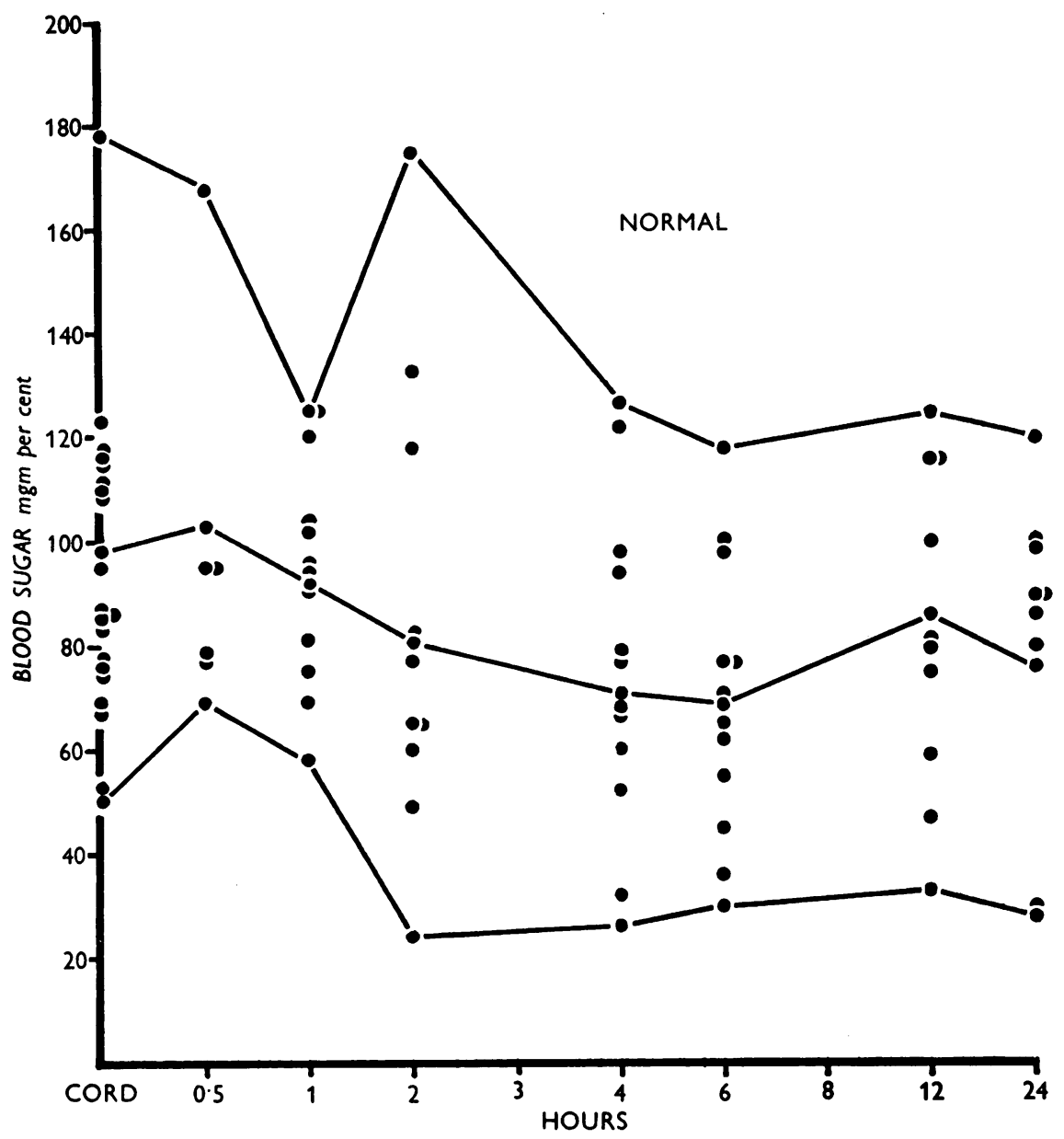

FIG. 1.-Normal controls.

rise or fall of blood sugar and it suggests that the majority of newborn infants soon attain a reasonably stable blood sugar level. The infants concerned had normal births with uncomplicated neonatal periods: in spite of the fact that four of the results were below $30 \mathrm{mg}$. \% no symptoms suggesting hypoglycaemia were observed.

The results obtained in the babies born of diabetic mothers showed considerable variation with a marked drop in blood sugar level during the first two or three hours of life. Once this drop occurred the disturbed $(D-g)$. It can be seen that there is no significant difference between the average figures plotted(Fig.4), although the figures in the $\mathrm{D}+\mathrm{g}$ group are slightly higher. It is felt, therefore, that there is no indication for the routine administration of oral glucose solutions to the infants born of diabetic mothers. One is lead to this decision by the figures recorded and by the knowledge that these children behave as premature babies and must be treated as such: many of them require oxygen during the first hours of life because of respiratory distress; in 
addition drowsiness and a poor cough reflex are often found and one is of the opinion that the early routine administration of fluid solutions with the resulting disturbance of the child might give rise to in these babies and to determine whether this state contributes to the high mortality rate.

Several workers have commented upon the remarkable absence of any unusual symptoms in

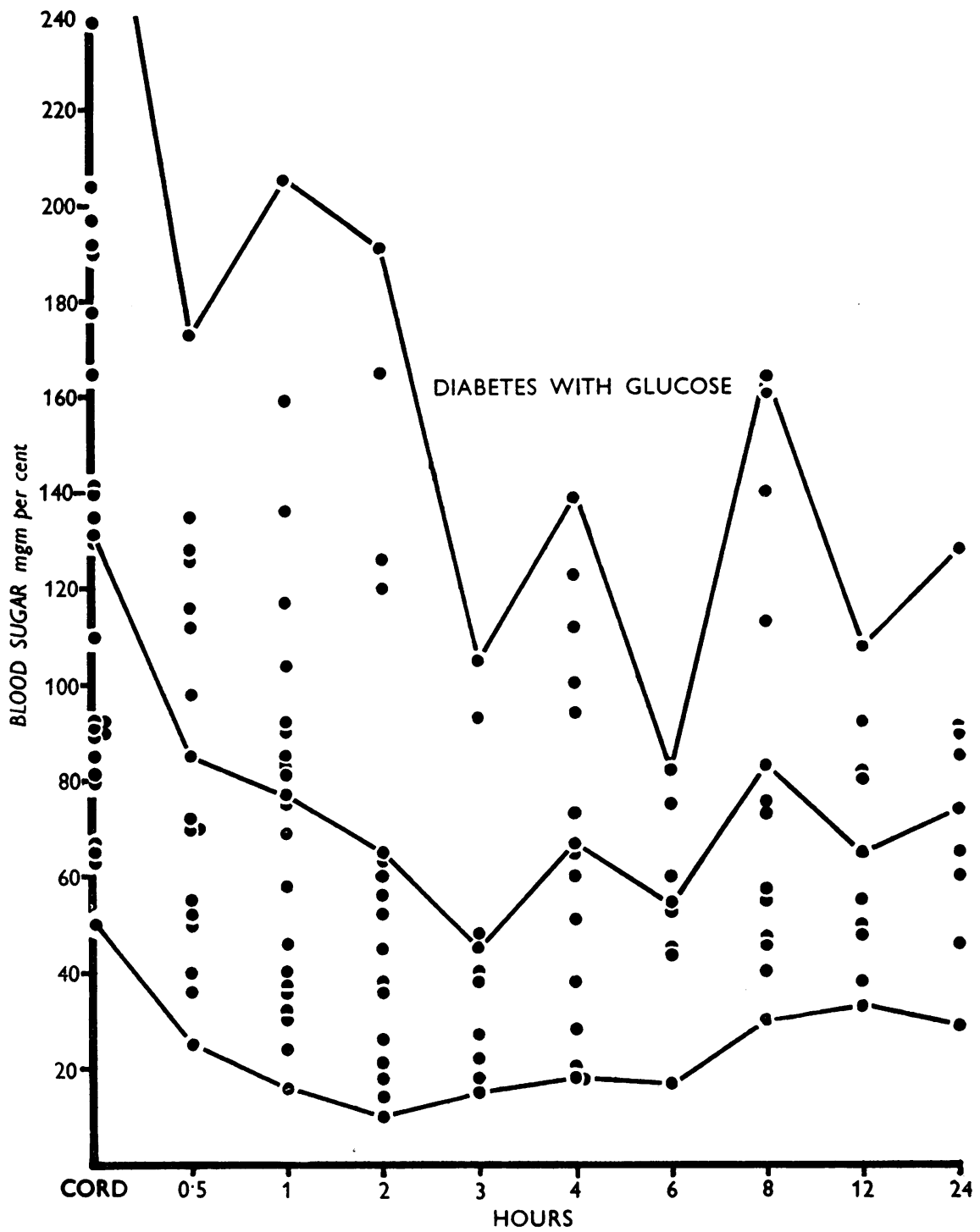

FIG. 2.-Babies born of diabetic mothers given glucose $(\mathrm{D}+\mathrm{g}$.)

more harm than good. It has, therefore, been decided to reserve the oral glucose solution for those babies presenting the clinical signs of hypoglycaemia.

The final and main purpose of this study is an attempt to assess what constitutes hypoglycaemia premature or new-born babies presenting with very low blood sugar levels (Joslin et al., 1952; Norval et al., 1950; Oakley, 1953; Pedersen, 1952; Sheumack, 1949; Smith, 1951). In a recent paper Oakley (1953) estimated the blood sugar levels at two-hourly intervals in a series of 35 children, of whom 17 
received $50 \%$ glucose. He does not give his results in detail but says that very low levels were estimated in children who survived satisfactorily: in three

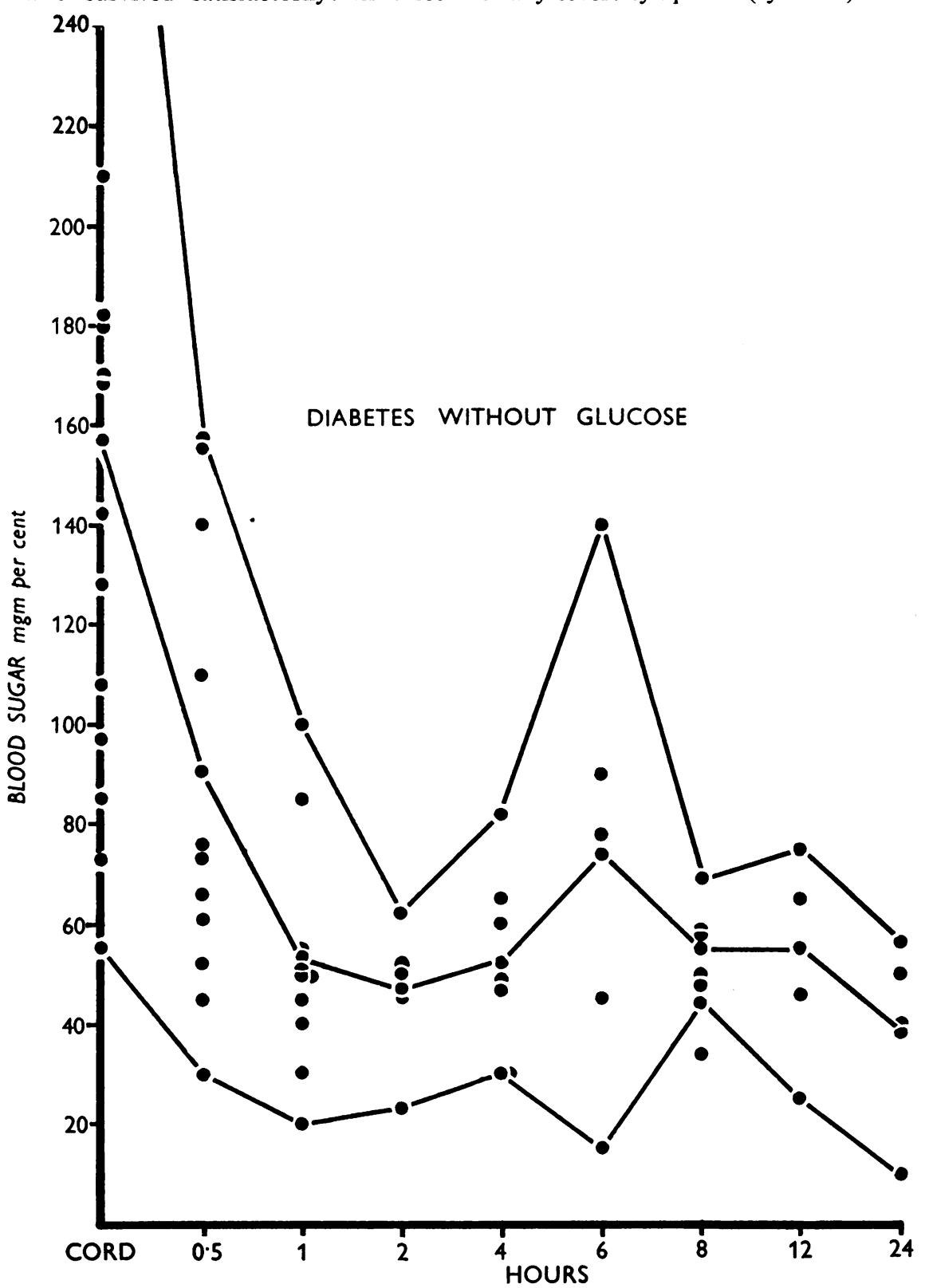

Fig. 3.-Babies born of diabetic mothers not given glucose $(D-g$.)

infants who died the blood sugar levels dropped to $35 \mathrm{mg}$., or less, per $100 \mathrm{ml}$. Pedersen (1952) in a comprehensive study of blood glucose levels in the infants born of diabetic mothers, says that clinical symptoms of hypoglycaemia were not observed in the first 24 hours of life, and suggests that the onset of any severe symptoms (cyanosis, twitching, grunt- 


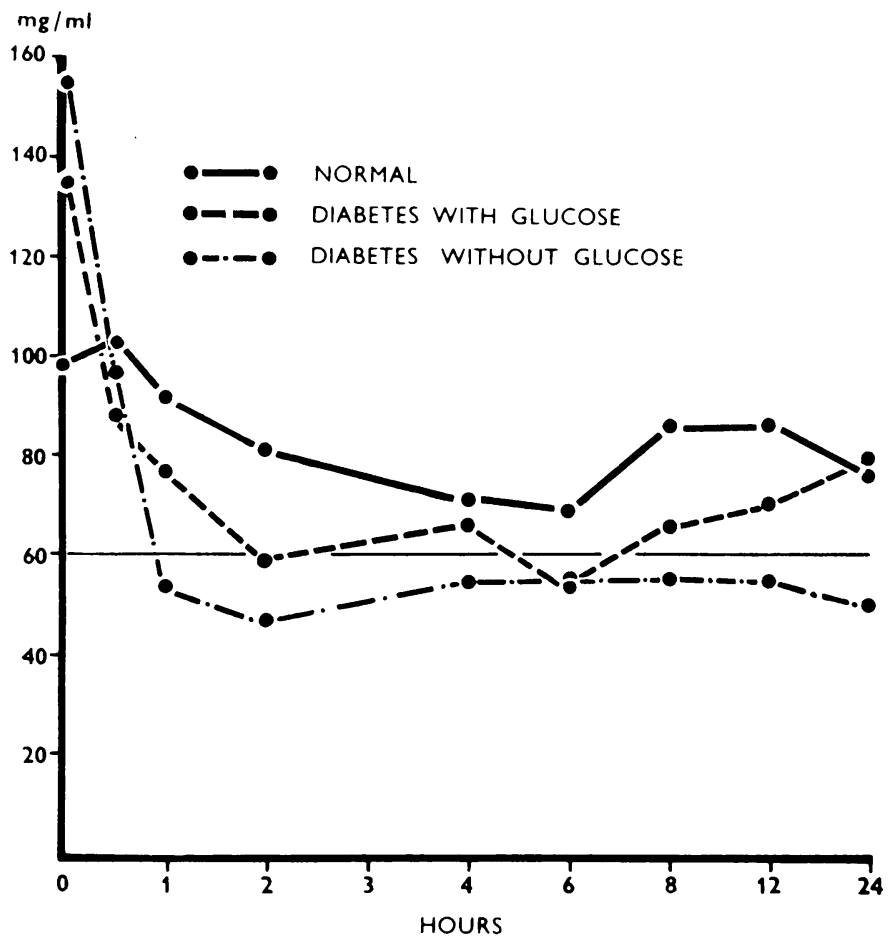

Fig. 4.-Comparison of the average mean in Figs. 1-3.

TABLE 2

BABIES BORN OF DIABETIC MOTHERS GIVEN GLUCOSE

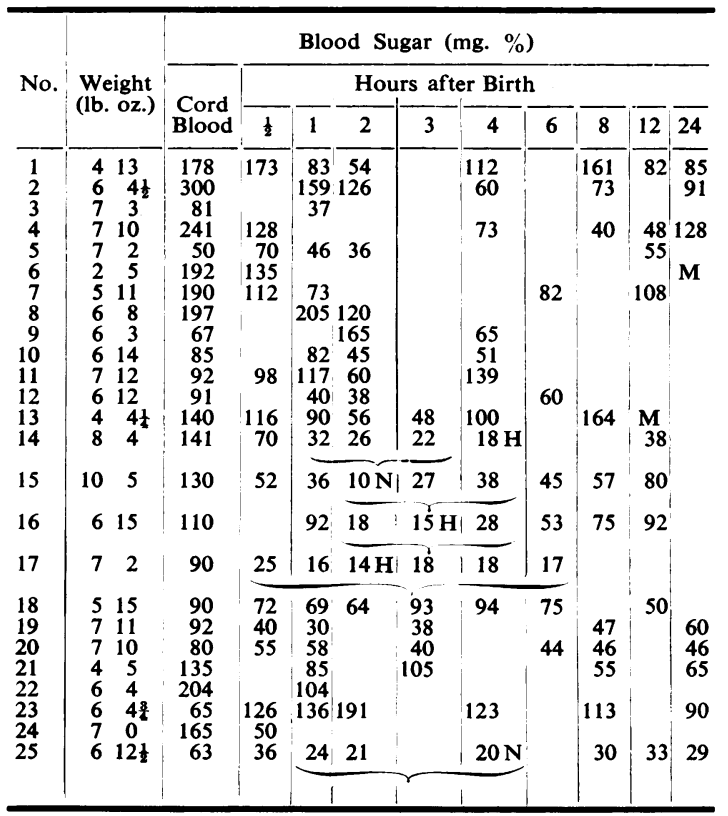

$M=$ death; $\mathbf{H}=$ hypoglocaemia $; \mathbf{N}=$ no symptoms.
It can be seen (Tables 2 and 3 ) that the blood sugar levels in our cases frequently fell below $40 \mathrm{mg}$. \%, a level which Hartmann and Jaudon (1937) suggested was (Tables 2 and 3 ) indicative of moderate hypoglycaemia, and many were below $35 \mathrm{mg}$. \%. In spite of the most careful clinical observations we saw only four children in whom the symptoms suggested hypoglycaemia; in these infants pallor, a sudden drop in temperature, shallow respirations and occasional twitching were noted. The recorded blood sugars in three cases were as follows: $14 \mathrm{mg}$., $18 \mathrm{mg}$. and $18 \mathrm{mg}$. \% respectively; the other infant experienced a rapid drop of $226 \mathrm{mg}$. \% in one hour. There were, in contrast, infants with levels of $10 \mathrm{mg}$., $15 \mathrm{mg}$. and $20 \mathrm{mg}$. \% who were symptom free.

It is our belief that, in spite of the low blood sugar levels recorded in the first hours of life of the babies of diabetic mothers, the clinical picture of hypoglycaemia is very rare as all infants are more capable of accommodating themselves to sudden reductions and low levels of blood sugar than are their elders. In this series of 'diabetic' babies there have been seven deaths and Table 4 describes the pathological diagnoses and the recorded blood sugar levels. In each case there was an obvious cause of death, intracranial haemorrhage being the commonest factor. The infant Sefton did have a rapid fall of blood sugar in the first hour, but as his cord haemoglobin was $75 \%$ and his condition desperate from birth, it is our opinion that the subcapsular

TABLE 3

BABIES BORN OF DIABETIC MOTHERS NOT GIVEN GLUCOSE

\begin{tabular}{|c|c|c|c|c|c|c|c|c|c|c|c|}
\hline \multirow{3}{*}{ No. } & \multirow{3}{*}{$\begin{array}{l}\text { Weight } \\
\text { (lb. oz.) }\end{array}$} & \multicolumn{10}{|c|}{ Blood Sugar (mg. \%) } \\
\hline & & \multirow{2}{*}{$\begin{array}{l}\text { Cord } \\
\text { blood }\end{array}$} & \multicolumn{7}{|c|}{ Hours after Birth } & \multirow[b]{2}{*}{12} & \multirow[b]{2}{*}{24} \\
\hline & & & $\frac{1}{2}$ & 1 & 2 & 3 & 4 & 6 & 8 & & \\
\hline $\begin{array}{r}1 \\
2 \\
3 \\
4 \\
5 \\
6 \\
7 \\
8 \\
9 \\
10 \\
11\end{array}$ & $\begin{array}{rl}6 & 9 \\
6 & 0 \\
5 & 83 \\
8 & 2 \\
9 & 6 \\
5 & 7 \\
12 & 6 \\
3 & 11 \\
8 & 2 \\
7 & 6 \\
8 & 12\end{array}$ & $\begin{array}{r}55 \\
85 \\
142 \\
97 \\
210 \\
\\
180 \\
73 \\
182 \\
\\
290\end{array}$ & \begin{tabular}{|c|}
73 \\
140 \\
110 \\
52 \\
157 \\
45 \\
$76 \mathrm{H}$
\end{tabular} & \begin{tabular}{|c|}
85 \\
51 \\
\\
54 \\
50 \\
30 \\
100 \\
50 \\
45 \\
$20 \mathrm{~N}$
\end{tabular} & $\begin{array}{l}50 \\
48 \\
\\
23 \\
46 \\
52 \\
\\
66\end{array}$ & & $\begin{array}{l}65 \\
49 \\
47\end{array}$ & $\begin{array}{c}78 \\
140 \\
M \\
90 \\
45\end{array}$ & $\begin{array}{l}M \\
48 \\
\\
50 \\
44\end{array}$ & $\begin{array}{l}25 \\
65\end{array}$ & $\begin{array}{l}50 \\
56\end{array}$ \\
\hline $\begin{array}{l}12 \\
13 \\
14 \\
15\end{array}$ & $\begin{array}{cc}8 & 8 \\
6 & 12 \frac{1}{4} \\
7 & 7 \\
4 & 10 \frac{1}{2}\end{array}$ & $\begin{array}{l}169 \\
128 \\
170 \\
108\end{array}$ & $\begin{array}{r}156 \\
66 \\
30 \\
61\end{array}$ & $\begin{array}{l}55 \\
40\end{array}$ & & & $30^{\prime}$ & $15 \mathrm{~N}$ & $\begin{array}{l}58 \\
34\end{array}$ & 46 & $\begin{array}{l}M \\
10\end{array}$ \\
\hline
\end{tabular}

$\mathbf{M}=$ death; $\mathbf{H}=$ hypoglocaemia $; \mathbf{N}=$ no symptoms. 
TABLE 4

DETAILS OF NEONATAL DEATHS

\begin{tabular}{|c|c|c|c|c|c|c|c|c|c|c|c|c|c|}
\hline \multirow{2}{*}{\multicolumn{2}{|c|}{ Initials }} & \multirow{2}{*}{\multicolumn{2}{|c|}{ Maturity }} & \multicolumn{7}{|c|}{ Blood Sugar Levels (mg. \%) } & \multirow{2}{*}{ Lived } & \multirow{2}{*}{ Anatomical Diagnosis } & \multirow{2}{*}{$\begin{array}{l}\text { Weight } \\
\text { (lb. oz.) }\end{array}$} \\
\hline & & & & 0 & $1 \quad \frac{1}{2}$ & 1 & 2 & 4 & 8 & 12 & & & \\
\hline C.G. & $\cdots$ & 36 & weeks & 140 & 116 & 90 & 56 & 48 & 100 & 164 & 13 hours & $\begin{array}{l}\text { Hyaline membrane } \\
\text { Haematoma liver } \\
\text { Follicular ovarian cysts }\end{array}$ & 44 \\
\hline Sefton & $\cdots$ & 35 & " & 140 & -30 & & & & & & $10 \quad "$ & $\begin{array}{l}\text { Subcapsular haematoma liver } \\
\text { Prematurity }\end{array}$ & 57 \\
\hline S.W. & $\cdots$ & 33 & , & 73 & 52 & 50 & 15 & 20 & & & $6 \frac{1}{2} \quad "$ & $\begin{array}{l}\text { Intra- and peri-ventricular haemorrhage } \\
\text { Hyaline membrane } \\
\text { Atelectasis } \\
\text { Prematurity }\end{array}$ & 311 \\
\hline Stephen & $\ldots$ & 36 & , & 169 & 156 & 55 & & & 58 & & $20 \quad$ " & $\begin{array}{l}\text { Hyaline membrane } \\
\text { Atelectasis lung }\end{array}$ & 88 \\
\hline M.D. & $\cdots$ & 31 & " & No & sugars & done & (too ill & & & & $15 \quad$, & $\begin{array}{l}\text { Intraventricular and subarachnoid haemorrhage } \\
\text { Subcapsular haematoma liver } \\
\text { Asphyxia }\end{array}$ & 47 \\
\hline W.H. & $\cdots$ & 32 & , & No & sugars & done & (too ill & & & & 3 , & $\begin{array}{l}\text { Intraventricular cerebral haemorrhage } \\
\text { Prematurity }\end{array}$ & 59 \\
\hline D.B. &. & 36 & " & 192 & 135 & & & & & & 5 days & $\begin{array}{l}\text { Tiny baby (twin) } \\
\text { Meningo-myelocoele }\end{array}$ & 25 \\
\hline
\end{tabular}

bleeding occurred before birth, and that the subsequent lowering of the blood sugar was not a major contributory factor to death. (In this case respiration was never properly established and gentle rocking was employed together with oxygen therapy for several hours.)

The low figure in the case S.W. was associated with symptoms suggesting hypoglycaemia, but in view of the necropsy findings it is unlikely that death was hastened by the hypoglycaemia. There is no evidence that this condition contributed to death in any of the other cases recorded here.

\section{Summary}

Estimations of the blood sugar level during the first 24 hours of life were made on 21 normal infants and 40 infants born of diabetic mothers. Twenty-five of the latter 40 babies were given $50 \%$ glucose in the first eight hours of life.

The normal infants showed a wide scatter of blood sugar levels but there was no dramatic rise or fall in the figures in any one case.

The babies of diabetic mothers revealed a rapid drop in the first hours of life with a slow rise towards the end of the first 24 hours. There were considerable variations in the figures obtained.

The administration of a $50 \%$ oral glucose solution did not make any appreciable difference to the blood sugar levels obtained compared with the group of infants to whom glucose was denied.
The clinical picture of hypoglycaemia in infancy is described and the fact that it is an uncommon finding is stressed.

It is suggested that few, if any, babies born of diabetic mothers die as the result of hypoglycaemia.

I am grateful to Professor W. I. C. Morris and Professor W. F. Gaisford for the opportunity to carry out this work. I am much indebted to Mr. H. Varley and the staff of the biochemical department for their assistance and to the various paediatric residents who have assisted in the general supervision of these cases. Finally, my thanks are due to the Department of Medical Illustration at the United Manchester Hospitals for their help with the graphs.

\section{REFERENCES}

Creery, R. D. G and Parkinson, T. J. (1953), Archives of Disease in Childhood 28, 134

Greenwald, H. M. and Pennell, S. (1930). Ibid., 39, 281.

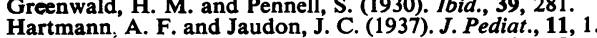

Haslewood, G. A. D. and Strookman, T. A. (1939). Biochem. J., 33, 920

Joslin, E. P., Root, H. F., White, P. and Marble, A. (1952). The Treatment of Diabetes Mellitus, 9th ed. London.

Ketteringham, R. C. and Austin, B. R. (1938). Amer. J. med. Sci., 195, 318.

McKittrick, J. B. (1940). J. Pediat., 16, 151.

Miller, H. C. and Ross, R. A. (1940). Ibid., 16, 473.

Norval, M. A., Kennedy, R. L. J. and Berkson, J. (1949). Ibid., 34, 342. Oak $\frac{}{\text { W }}$ (1953). Ibid., 11, 1. 36, 177

Pedersen, J. (1952). Diabetes and Pregnancy. Blood Sugar of Newborn Infants. Copenhagen.

Peel, J. and Oakley, W. (1950). Trans. XII Brit. Cong. Obstet. Gynec. 1949, 161. London.

Reiss, R. A., DeCosta, E. J. and Allweiss, M. D. (1950). Amer. J. Obstet. Gynec., 60, 1023.

Sheumack, D. R. (1949), Med. J. Aust., $2,553$.

Smith, C. A. (1951). The Physiology of the Newborn Infant, 2nd ed. Oxford.

Wachter, H. E. (1949). J. Mo. med. Ass., 46, 837. 